Tropical Journal of Pharmaceutical Research December 2011; 10 (6): 739-746

(C) Pharmacotherapy Group, Faculty of Pharmacy, University of Benin

Benin City, 300001 Nigeria.

All rights reserved.

Available online at http://www.tjpr.org

Research Article

http://dx.doi.org/10.4314/tjpr.v10i6.6

\title{
Ethyl Alcohol Extract of Hizikia fusiforme Induces Caspase-dependent Apoptosis in Human Leukemia U937 Cells by Generation of Reactive Oxygen Species
}

\author{
Chang-Hee Kang ${ }^{1}$, Sang-Hyuck Kang ${ }^{1}$, Sung-Hwan Boo ${ }^{1}$, Sung-Young \\ Park $^{2}$, Yung H Choi ${ }^{3}$, Dong-Oh Moon ${ }^{4}$ and Gi-Young Kim ${ }^{1^{*}}$ \\ ${ }^{1}$ Laboratory of Immunobiology, Department of Marine Life Sciences, Jeju National University, Jeju 690-756, ${ }^{2}$ \\ OTTOGI Research Institute, OTTOGI Ltd., Gyeonggi-do 431-070, ${ }^{3}$ Department of Biochemistry, College of Oriental \\ Medicine, Dongeui University, Busan 614-054, ${ }^{4}$ Department of Biology Education, College of Education, Daegu \\ University, Gyeongsan, Gyeongbuk 712-714, Republic of Korea
}

\begin{abstract}
Purpose: Hizikia fusiforme is renowned for the possession of anti-inflammatory and anti-oxidant properties. In this study, the role of the ethyl alcohol extract of $\mathrm{H}$. fusiforme (EAHF) in the induction of apoptosis in human leukemia U937 cells was investigated.

Methods: Protein expression was investigated by Western blot analysis. Cell viability and apoptosis were analyzed by an MTT assay and flow cytometric analysis. Caspase activity was analyzed using a caspase-specific kit.

Results: EAHF suppressed the proliferation of U937 cells in a dose-dependent manner. This effect was closely related to the induction of apoptosis via the downregulation of IAP family members such as IAP1, IAP-2 and XIAP, as well as Bcl-2 proteins. The results also showed that caspases play an essential role in EAHF-induced apoptosis by generating of reactive oxygen species (ROS). In addition, ROS scavenging by $\mathrm{N}$-acetyl-L-cysteine (NAC) and glutathione (GSH) decreased EAHF-induced apoptosis via the suppression of caspase activity. Although EAHF induced the phosphorylation of mitogenactivated protein kinases (MAPKs), treatment with MAPK inhibitors did not affect EAHF-induced apoptosis.

Conclusion: These results suggest that EAHF induces apoptosis in U937 cells via ROS-dependent caspase activation.
\end{abstract}

Keywords: Hizikia fusiforme, Apoptosis, Caspase, Reactive oxygen species 


\section{INTRODUCTION}

Hizikia fusiforme is an edible brown seaweed, which is widely distributed in the coastal areas of Korea, Japan, and China. It is broadly used as an Oriental herbal medicine [1]. A recent study reported that $H$. fusiforme contains a number of compounds possessing anti-inflammatory, anti-oxidant and anticoagulant proprieties [2]. Previous research has reported that $H$. fusiforme has a variety of physiological activities, such as reactive oxygen species (ROS) scavenging and lipid oxidation inhibitory effects [3]. Recently, we demonstrated that the ethyl alcohol extract of $H$. fusiforme (EAHF) sensitizes cancer cells to apoptosis through the tumor necrosis factor-related apoptosis-inducing ligand (TRAIL), although no cytotoxicity was reported at low concentrations of EAHF itself [4].

Apoptosis is genetically programmed cell death, which is necessary for the control of cell numbers during natural development, the removal of unwanted or damaged cells, and the continuation of tissue homeostasis in multicellular organisms [5]. The significance of cell death via apoptosis is currently recognized [6]. The absence of cellular control can lead to several diseases such as cancer, AIDS and Alzheimer disease [7]. Elucidation of apoptotic mechanism is important for the prevention and cure of various currently incurable diseases such as cancer and AIDS [9]. Apoptosis suppression in various cancer cells is known to cause tumor growth and resistance to cytotoxic anticancer agents.

Apoptosis occurs through 2 main pathways, namely mitochondria-mediated and death receptor-mediated pathways. These 2 apoptotic signals are transmitted together to effector molecule caspase- 3 and then to other nucleases and proteases such as poly (ADP-ribose) polymerase (PARP), which are involved in a number of cellular processes related mainly to DNA repair and apoptosis [9]. Caspase-3, in particular, is a prerequisite for the management of cell death by diverse apoptotic stimuli [10]. Its activation is influenced by diverse cellular proteins such as inhibitor of apoptosis proteins (IAP) and $\mathrm{Bcl}-2$ family proteins [11]. Apoptosis also has distinguishing properties such as cell shrinkage, chromatin condensation, DNA fragmentation, and nuclear collapse without inflammation [5].

Reactive oxygen species (ROS) perform vital roles in regulating various functional pathways such as cell proliferation, cellular transformation, and apoptosis [12]. In addition, it is well known that oxidative stress is a notable factor in the initiation and progression of many diseases including Parkinson and Alzheimer diseases as well as cancer [13]. Excessive ROS generation induces apoptosis in a variety of cancer cells through mitochondrial dysfunction due to alterations in oncogenic proteins such as $\mathrm{H}$ Ras and FK228 [14].

In this study, we investigated whether EAHF itself induces apoptosis in human leukemia U937 cells. Our results showed that EAHF sensitizes apoptosis through ROS-dependent caspase activation.

\section{EXPERIMENTAL}

\section{Preparation of EAHF}

EAHF was obtained from Institute of Oriental Medicine (Dongeui University, Busan, Republic of Korea). Briefly, fresh $H$. fusiforme was washed three times with tap water to remove salt, epiphyte and sand on the surface of the samples before storage $-20^{\circ} \mathrm{C}$. The frozen samples were lyophilized and homogenized using a grinder before extraction. The dried powder was extracted with ethyl alcohol and evaporated in vacuo.

\section{Antibodies and reagents}

Antibodies against caspase-3, caspase-8, caspase-9, PARP, IAP-1, IAP-2, XIAP, and $\mathrm{Bcl}-2$ were purchased from Santa Cruz 
Biotechnology (Santa Cruz, CA, USA). Antibodies against JNK, phosphor (p)-JNK, ERK, p-ERK, p38, and p-p38 were purchased from Cell Signal (Beverly, MA, USA). Antibody against $\beta$-actin was obtained from Sigma (St. Louis, MO, USA). 6-Carboxy-2',7'dichlorofluorescein diacetate (DCFDA) and 3,3'-dihexyloxacarbocyanine iodide $\left(\mathrm{DiOC}_{6}\right)$ were purchased from Molecular Probes (Eugene, OR, USA). Glutathione (GSH) and $\mathrm{N}$-acetyl-L-cysteine (NAC) were purchased from Sigma (St. Louis, MO, USA). PD98059, SP600125, SB239063, and z-VAD-fmk were purchased from Calbiochem (San Diego, CA, USA).

\section{Cell line and cell growth assay}

Human leukemia U937 cells were cultured in RPMI1640 (Life Technologies, Grand Island, NY, USA) supplemented with $10 \%$ fetal bovine serum and antibiotics (WelGENE Inc., Daegu, Republic of Korea). Cells were seeded at a density of $1 \times 10^{5}$ cells $/ \mathrm{ml}$, incubated for $24 \mathrm{~h}$, and then treated with the indicated concentrations of EAHF. 3-(4,5dimethylthiazol-2-yl)-2,5-diphenyltetrazolium bromide (MTT) assays were used to determine cell viability.

\section{Detection of apoptosis}

Flow cytometric analysis was used to assess the ratio of apoptosis, mitochondrial membrane potential, and cell distribution. Briefly, cells $\left(1 \times 10^{6}\right)$ were fixed in $70 \%$ ethanol overnight at $4{ }^{\circ} \mathrm{C}$ and washed in phosphate-buffered saline (PBS) with $0.1 \%$ BSA. Cells were then incubated with $1 \mathrm{U} / \mathrm{ml}$ of RNase A (DNase free) and $10 \mu \mathrm{g} / \mathrm{ml}$ of propidium iodide (PI; Sigma) overnight at room temperature in the dark. The level of apoptotic cells containing sub-G ${ }_{1}$ DNA content was determined as a percentage of the total number of cells. For $\mathrm{Pl} /$ annexin- $\mathrm{V}$ and $\mathrm{DiOC}_{6}$ staining, live cells were washed with PBS and then incubated with annexin-V fluorescein isothiocyanate (Koma Biotechnology, Seoul, Republic of Korea) and $\mathrm{DiOC}_{6}$. FACSCalibur flow cytometer (Becton
Dickenson, San Jose, CA, USA) was used to analyze the cells.

\section{Western blotting assay}

Total cell extracts were prepared using PROPREP protein extraction solution (iNtRON Biotechnology, Sungnam, Republic of Korea). Total cell extracts were separated on polyacrylamide gels and then standard procedures were used to transfer them to the nitrocellulose membranes. The membranes were developed using an ECL reagent (Amersham, Arlington Heights, IL, USA).

\section{Measurement of ROS}

Cells were plated at a density of $5 \times 10^{4}$, allowed to attach for $24 \mathrm{~h}$, and exposed to 5 $\mathrm{mM}$ of NAC alone, $5 \mathrm{mM}$ of $\mathrm{GSH}$ alone, 30 $\mu \mathrm{g} / \mathrm{ml}$ of EAHF alone, or NAC or GSH plus EAHF for $1 \mathrm{~h}$. The cells were stained with 10 $\mu \mathrm{M}$ of DCFDA for $10 \mathrm{~min}$ at $37^{\circ} \mathrm{C}$, and flow cytometry was used to determine the fluorescence intensity of DCFDA in the cells.

\section{In vitro caspase activity assay}

A caspase activation kit was used according to the manufacturer's protocol to measure the activity of caspase-like protease. This assay is based on spectrophotometric detection of the color reporter molecule $p$-nitroaniline (pNA) that is linked to the end of the caspase-specific substrate. The cleavage of the peptide by the caspase releases the chromophore pNA, which can be quantified spectrophotometrically at a wavelength of $405 \mathrm{~nm}$. Ac-DEVD-pNA (for caspase-3), AcIETD-pNA (for caspase-8), and LEHD-pNA (for caspase-9) were used as the substrates.

\section{Statistical analysis}

All data were derived from at least three independent experiments. Statistical analyses were conducted using SigmaPlot software (version 11.0) Values were presented as mean \pm SE. Significant differences between the groups were 
determined using the two-way ANOVA test. Statistical significance was regarded at $p<$ 0.05 .

\section{RESULTS}

\section{EAHF induces apoptosis in human leukemia U937 cells}

Treatment with EAHF suppressed cell viability in a dose-dependent manner at concentrations exceeding $30 \mu \mathrm{g} / \mathrm{ml}$ (Fig 1A). EAHF treatment resulted in a significant increase of $\mathrm{Pl}^{+} /$annexin- $\mathrm{V}^{+}$populations, suggesting that EAHF induces apoptosis in a dose-dependent manner. In particular, 50 $\mu \mathrm{g} / \mathrm{ml}$ of EAHF conducted the double-positive populations to $24.7 \%$ in U937 cells (Fig 1B). Furthermore, treatment with concentrations higher $30 \mu \mathrm{g} / \mathrm{ml}$ of EAHF enhanced morphological characteristics, including cell shrinkage observed under light microscopy (Fig 1C). These data indicate that high concentrations of EAHF itself are capable of

A

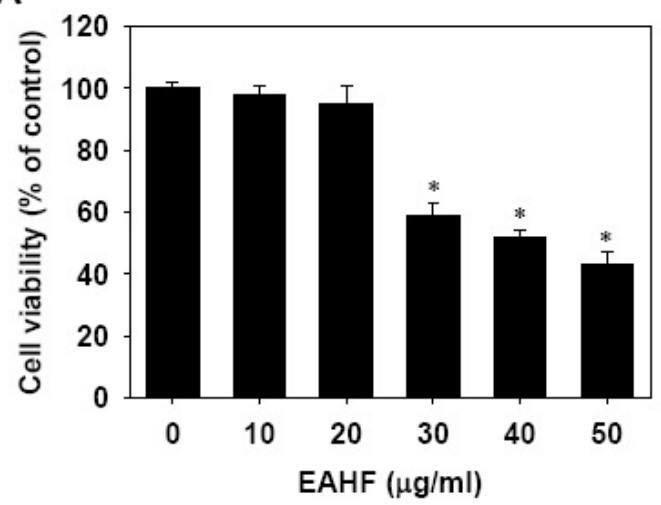

inducing apoptosis with cell morphological changes.

\section{Caspases are potential regulators in EAHF-induced apoptosis}

Results of studies on the effect of EAHF on caspase activation are shown in Fig 2 . Treatment with EAHF for $24 \mathrm{~h}$ significantly increased the cleaved forms of caspases -3, 8, and -9 , and PARP in U937 cells (Fig 2A). Moreover, EAHF resulted in an increase in the activity caspases $-3,-8$, and -9 activity in a dose-dependent manner (Fig 2B). EAHF treatment reduced the expression of antiapoptotic proteins, Bcl-2, IAP-1, IAP-2, and $\mathrm{XIAP}$ in a dose-dependent manner (Fig 2C). Pretreatment with z-VAD-fmk significantly decreased EAHF-induced annexin- $\mathrm{V}^{+}$(Fig 2D) and sub-G $\mathrm{G}_{1}$ phase populations (Fig 2E). These data indicated that the activation of caspases is a potential effector in EAHFinduced apoptosis.

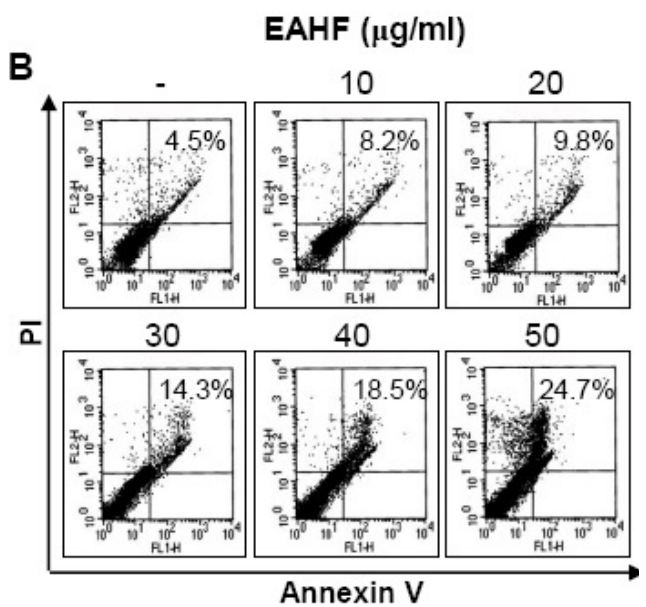

C

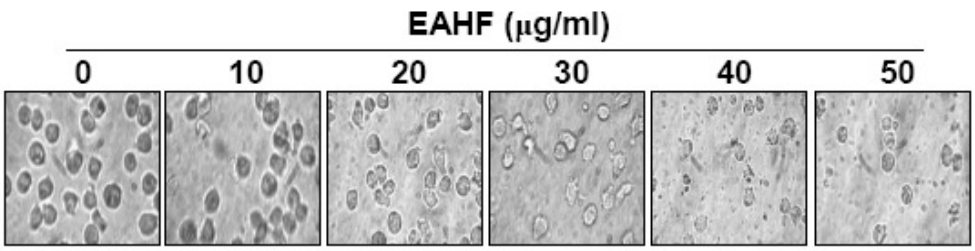

Fig. 1: Effect of EAHF on U937 cell viability (A), $\mathrm{PI}^{+} /$annexin- $\mathrm{V}^{+}$staining $(\mathrm{B})$ and $\mathrm{U} 937$ cell morphology. Data represent the mean \pm SE $(n=3)$ 
A

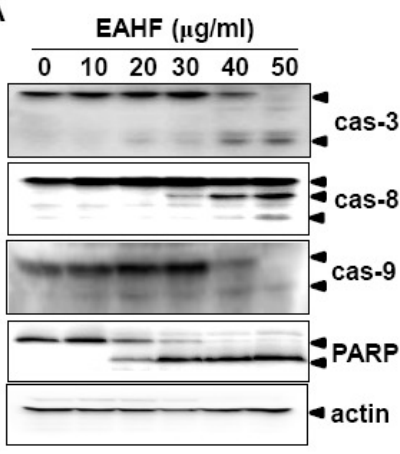

B

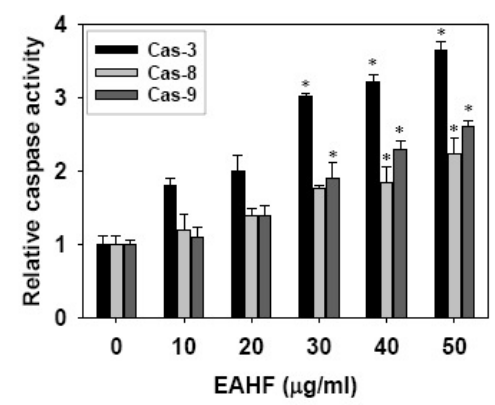

C

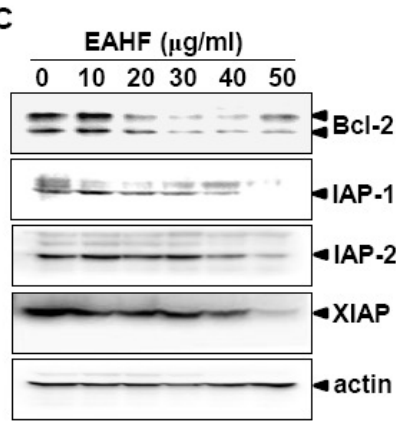

D
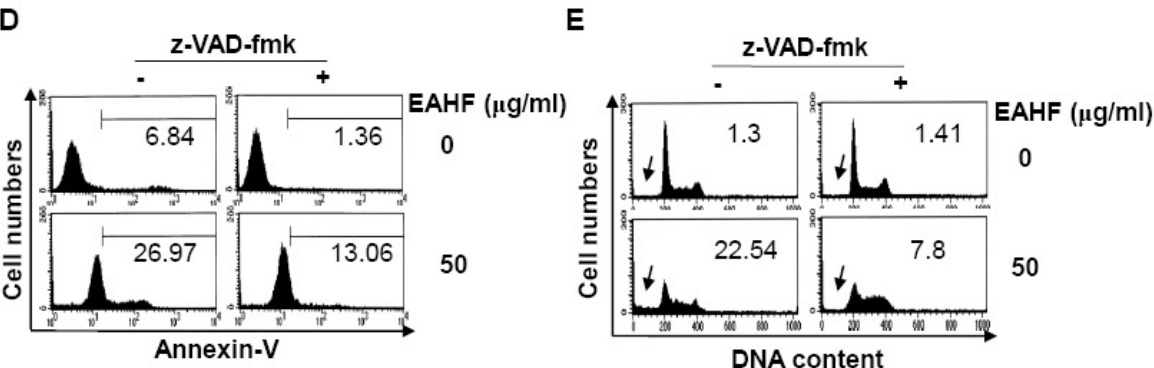

Fig 2: Effect of EAHF on caspase expression (A), caspase activities (B), anti-apoptotic factors (C) and apoptosis of U937 cells (D and E). Data represent the mean $\pm S E(n=3)$

\section{ROS generation is the first step in EAHF- induced apoptosis}

Consistent with the decrease in anti-apoptotic proteins (Fig. 2), the treatment of U937 cells with EAHF significantly lowered mitochondrial membrane potential in a dose-dependent manner (Fig 3A). Additionally, EAHF itself increased ROS generation and sub- $G_{1}$ populations. However, pretreatment with NAC or GSH significantly attenuated EAHFstimulated ROS generation (Fig 3B) and completely restored EAHF-induced sub- $\mathrm{G}_{1}$ populations (Fig $3 C$ ). Pretreatment with NAC or GSH also suppressed the cleavage of PARP induced by EAHF treatment (Fig 3D). In a parallel experiment, EAHF-induced caspase-3 activity was significantly suppressed in the presence of NAC or GSH (Fig 3E). These results indicate that ROS generation regulates apoptosis in U937 cells through caspase-3 activation.

\section{EAHF-induced apoptosis is not induced via the MAPK signal pathway}

EAHF treatmentfor $24 \mathrm{~h}$ led to increases in the phosphorylation of ERK, p38, and JNK in a dose-dependent manner (Fig 4A). However, none of the MAPK inhibitors could restore the loss of cell viability (Fig. 4B) and block the decrease of sub- $G_{1}$ phase populations induced by treatment with EAHF (Fig 4C). These results indicate that MAPKs might not be involved in EAHF-induced apoptosis.

\section{DISCUSSION}

Dietary habits can influence the progression of a variety of diseases, including cancers and inflammatory diseases [1,]. A number of studies are focusing on the evaluation of the anti-cancer and anti-inflammatory effects of seaweed extracts [15]. Recently the inhibitory properties of $H$. fusiforme on the production of pro-inflammatory mediators and ethanol- 


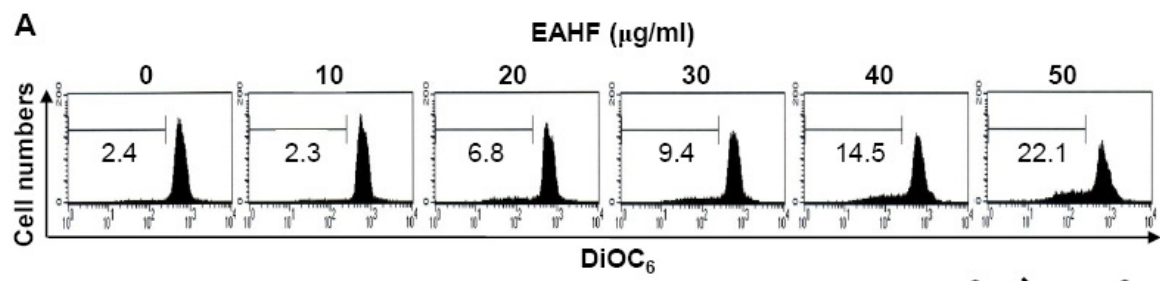

B
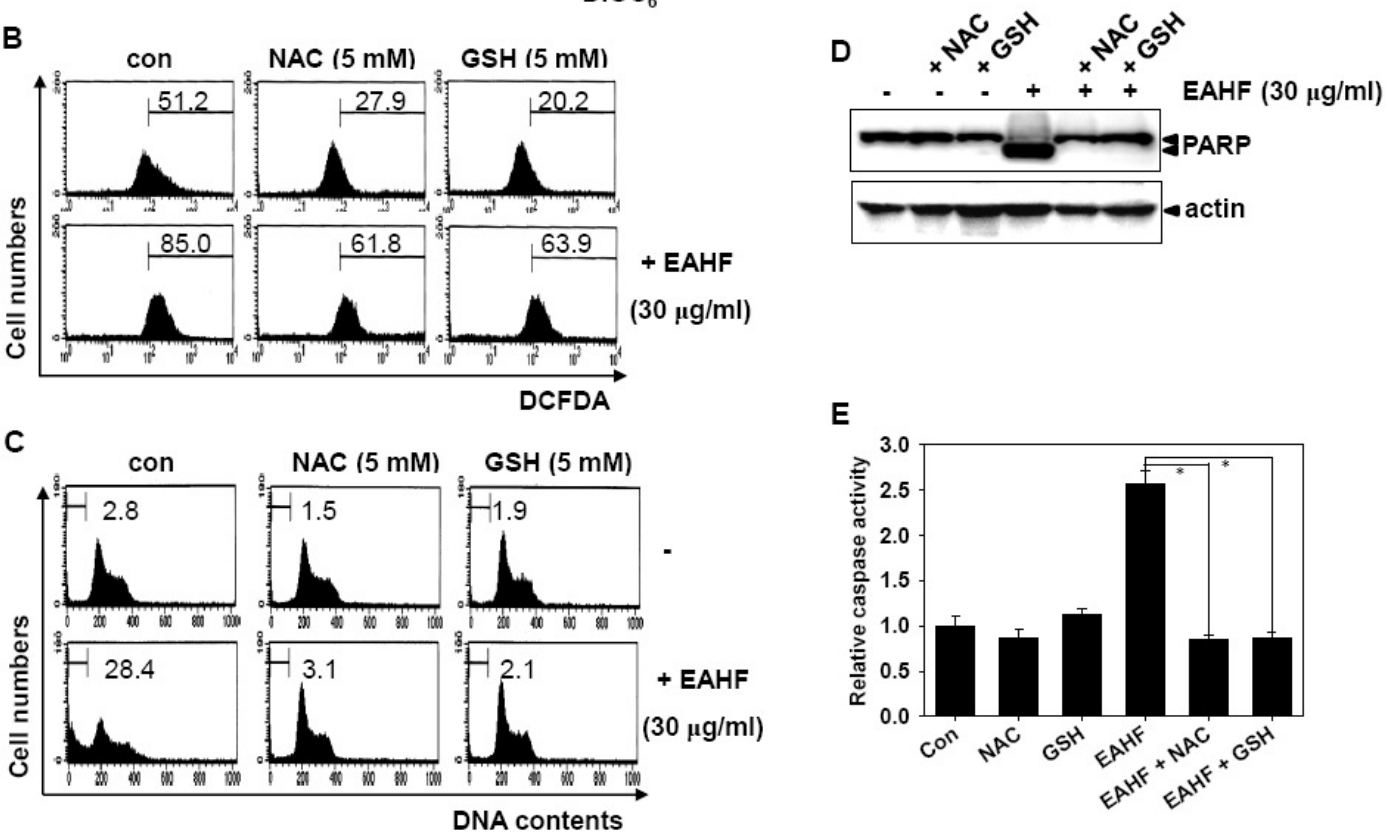

Fig 3: Effect of EAHF on mitochondrial membrane potential (A), ROS generation (B), apoptosis of ROS inhibitors (C), PARP expression (D) and caspase activity of U937 cells (E). Data represent the mean \pm SE $(n=3)$.
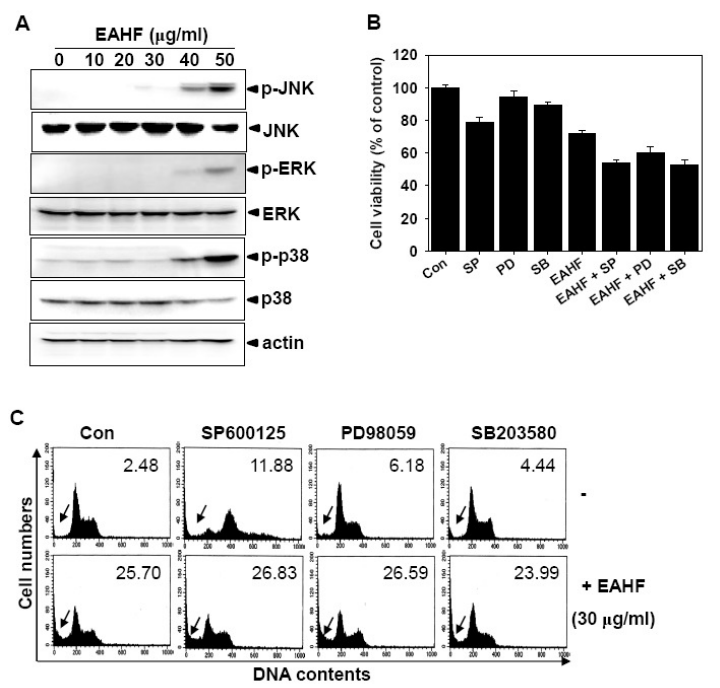

Fig. 4: Effect of EAHF on expression of MAPKs (A), cell viability (B), PI staining of U937 cells (E). Data represent the mean $\pm S E(n=3)$. 
induced cytotoxicity have been demonstrated $[2,16]$. Additionally, we previously reported that EAHF sensitizes TRAIL-induced apoptosis and inhibits matrix metalloproteinase activity as well as tight junction in cancer cells $[4,17]$. Before now, there were no reports on whether EAHF itself induces apoptosis in cancer cells. In this study, EAHF was shown to induce apoptosis in human leukemia U937 cells through ROS-dependent caspase activation.

The critical pathways of caspase activation have recently been assessed in relation to induction of apoptosis [5]. Once the caspase signal pathway is initiated and propagated by proteolytic autocatalysis, downstream molecules act to induce the cleavage of caspase substrates such as PARP, suggesting initiation of apoptosis [6]. In this study, we demonstrated that EAHF induces apoptosis through the activation of caspases. This is confirmed by the finding that treatment with EAHF in the presence of z-VAD-fmk significantly inhibited apoptosis. Recent studies also reported that ROS generation has been strongly implicated in caspasedependent apoptotic response induced by various chemotherapeutic agents [10]. Nevertheless, further experimental investigation is necessary to determine the association of ROS generation with caspase activation in EAHF-induced apoptosis.

The MAPK protein family is known to play critical roles in cell survival and death in many physiological and pathological conditions. It has been demonstrated that activation of p38 MAPK and JNK activates a variety of pro-apoptotic downstream effectors, whereas ERK is involved in cell survival and growth [18]. However, recent studies differ on the relationship between MAPKs and apoptosis under question. In this study, EAHF was shown to induce the phosphorylation of 3 types of MAPKs, namely, ERK, p38, and JNK. However, inhibition of MAPKs appears to have no influence on cell viability. In particular, various studies have revealed that ROS generation results in apoptotic cell death through a variety of mechanisms such as the activation of JNK [19]. However, in this study, ROS generation significantly increased JNK phosphorylation, but this was not linked with the JNK pathway in inducing apoptosis. Therefore, further investigation is required in order to determine the mechanisms associated with the phosphorylation of MAPKs.

\section{CONCLUSION}

In summary, our results suggest that EAHF induces apoptosis in human leukemia U937 cells through ROS-dependent caspase activation.

\section{ACKNOWLEDGMENT}

This study was supported by a grant from Jeju Sea Grant, Republic of Korea.

\section{REFERENCES}

1. Li B, Wei XJ, Sun JL, Xu SY. Structural investigation of a fucoidan containing a fucose-free core from the brown seaweed, Hizikia fusiforme. Carbohydr Res 2006; 341: 1135-1146.

2. Choi EY, Hwang HJ, Kim IH, Nam TJ. Protective effects of a polysaccharide from Hizikia fusiformis against ethanol toxicity in rats. Food Chem Toxicol 2009; 47: 134-139.

3. Karawita R, Siriwardhana N, Lee KW, Heo MS, Yeo $I K$, Lee YD, Jeon YJ. Reactive oxygen species scavenging, metal chelation, reducing power and lipid oxidation inhibition properties of different solvent fractions from Hizikia fusiformis. Eur Food Res Technol 2005; 220: 363-371.

4. Kim TY, Jin CY, Kim GY, Choi IW, Jeong YK, Nam TJ, Kim SK, Choi YH. Ethyl alcohol extracts of Hizikia fusiforme sensitize AGS human gastric adenocarcinoma cells to tumor necrosis factor-related apoptosis-inducing ligand-mediated apoptosis. J Med Food 2009; 12: 782-787.

5. Evans VG. Multiple pathways to apoptosis. Cell Biol Int 1993; 17: 461-476.

6. Steller $\mathrm{H}$. Mechanisms and genes of cellular suicide. Science 1995; 267: 1445-1449.

7. Beatty S, Koh H, Phil M, Henson D, Boulton M. The role of oxidative stress in the pathogenesis of age-related macular degeneration. Surv Ophthalmol 2000; 45: 115-134. 
8. de Almeida CJ, Linden R. Phagocytosis of apoptotic cells: a matter of balance. Cell Mol Life Sci 2005; 62: 1532-1546.

9. Jin Z, El-Deiry WS. Overview of cell death signaling pathways. Cancer Biol Ther 2005; 4: 139163.

10. Stennicke HR, Salvesen GS. Properties of the caspases. Biochim Biophys Acta 1998; 1387: 17-31.

11. Deveraux QL, Reed JC. IAP family proteinssuppressors of apoptosis. Genes Dev 1999; 13: 239-252.

12. Adler V, Yin Z, Tew KD, Ronai Z. Role of redox potential and reactive oxygen species in stress signaling. Oncogene 1999; 18: 61046111.

13. Jomova K, Jenisova Z, Feszterova M, Baros S, Liska $J$, Hudecova $D$, Rhodes CJ, Valko $M$. Arsenic: toxicity, oxidative stress and human disease. J Appl Toxicol 2011; 31: 95-107

14. Choudhary S, Wang KK, Wang HC. Oncogenic $H$ Ras, FK228, and exogenous $\mathrm{H}_{2} \mathrm{O}_{2}$ cooperatively activated the erk pathway in selective induction of human urinary bladder cancer j82 cell death. Mol Carcinog 2011; 50: 215-219.

15. Hwang $P A$, Chien $S Y$, Chan $Y L, L u M K, W u C H$, Kong ZL, Wu CJ. Inhibition of lipopolysaccharide (LPS)-induced inflammatory responses by Sargassum hemiphyllum sulfated polysaccharide extract in RAW 264.7 macrophage cells. J Agric Food Chem 2011; 59: 2062-2068.

16. Jung K, Ha E, Uhm Y, Park H, Kim MJ, Kim H, Baik $H$, Hong M, Yang J, Yim SV. Suppressive effect by Hizikia fusiforme on the production of tumor necrosis factor in BV2 murine microglial cells. Neurol Res 2007; 29: S88S92.

17. Kim SO, Choi YH. The ethyl alcohol extract of Hizikia fusiforme inhibits matrix metalloproteinase activity and regulates tight junction related protein expression in Hep3B human hepatocarcinoma cells. J Med Food 2010; 13: $31-38$

18. Cross TG, Scheel-Toellner D, Henriquez NV, Deacon E, Salmon M, Lord JM. Serine/threonine protein kinases and apoptosis. Exp Cell Res 2000; 256: 34-41.

19. Iwamaru $A$, Iwado $E$, Kondo $S$, Newman RA, Vera $B$, Rodríguez $A D$, Kondo $Y$. Eupalmerin acetate, a novel anticancer agent from Caribbean gorgonian octocorals, induces apoptosis in malignant glioma cells via the $c^{-}$ Jun NH2-terminal kinase pathway. Mol Cancer Ther 2007; 6: 184-192. 